\title{
PRODUÇÃO DE VÍDEO AULAS COMO FERRAMENTA EDUCACIONAL DA DISCIPLINA QUÍMICA NO ENSINO MÉDIO*
}

\author{
VIDEO PRODUCTION AS AN EDUCATION TOOL FOR HIGH SCHOOL \\ CHEMISTRY CLASSES
}

\author{
CLASES DE PRODUCCIÓN VIDEO EDUCACIÓN COMO HERRAMIENTA \\ DE LA QUÍMICA EN LA DISCIPLINA ESCOLAR
}

\author{
Andressa Rose Castro Costa \\ Dannila Coelho Maranhão Rocha \\ Efraim de Lucas Lima Mendes \\ Manoel de Jesus de Aquino Lima \\ Mats Vilandel Gonçalves dos Santos \\ José Alberto Pestana Chaves
}

\begin{abstract}
Resumo: O presente trabalho tem por objetivo despertar no aluno da educação básica, especialmente do ensino médio, a melhor compreensão da química, enquanto ciência experimental, pela realização de aulas práticas e o registro em vídeo desses experimentos. Para a maioria dos estudantes, a química é reconhecida como uma disciplina de difícil compreensão, que não desperta o interesse quanto à assimilação dos conteúdos, o que vem acarretando resultados negativos em relação à repetência e abandono por parte de uma grande quantidade de alunos matriculados na rede pública do nosso estado. Dessa forma, este trabalho apresenta a química de uma maneira diferente: aplicada, contextualizada, trabalhada pelo aluno, através de experimentos simples, rápidos, gravadas em vídeos para futuras postagens na internet ou para apresentação em sala de aula aos demais alunos da série.
\end{abstract}

Palavras-chave: Química. Ensino médio. Experimentos.

\begin{abstract}
This work aims at arousing in students of basic education, especially in high school students, a better understanding of chemistry as an experimental science, by conducting practical classes and video recording of those experiments. For most students, chemistry is recognized as a subject of difficult understanding, that does not arouse interest on the assimilation of the contents, which has been causing negative results regarding failure and abandonment by a large number of students enrolled in public schools of Maranhão State. Thus, this paper presents chemistry in a different way: applied, contextualized, worked by the student through simple experiments, fast, and recorded on video for future posts on the internet or for presentation in classrooms to other students in the grade.

Keywords: Chemistry. High School. Experiments

Resumen: Este trabajo tiene como objetivo despertar la educación básica de los estudiantes, especialmente en la educación secundaria, una mejor comprensión de la química como un experimento científico, para la realización de las clases prácticas y grabación de vídeo de estos experimentos. Para la mayoría de los estudiantes, la química es reconocido como un tema difícil de entender, no despierta el interés en la asimilación de los contenidos, que ha estado causando resultados negativos con respecto al fracaso y abandono por parte de un gran número de alumnos matriculados en las escuelas públicas de nuestro estado. Por lo tanto, este trabajo se presenta la composición química de una manera diferente: aplicada, contextualizado, elaborado por el estudiante a través de experimentos sencillos y rápidos, grabadas en vídeo para futuros posts en Internet o para su presentación en clase con otros estudiantes en el grado.
\end{abstract}

Palabras clave: Química. La escuela secundaria. Experimentos.

\section{INTRODUÇÃO}

A Química, por ser uma ciência acentuadamente experimental, desenvolveu raízes profundas no campo da pesquisa e tecnologia, mas apenas recentemente vem despertando para o campo do ensino. Apesar de incipiente em muitas Universidades, a pesquisa em ensino da Química vem se constituindo cada vez mais como um campo científico de estudo, através do estabelecimento de metodologias de investigação (teorias/modelos), estudos de casos, o que tem permitido o número crescente de publicações e a criação de periódicos específicos, tais como: a Química Nova na Escola (2012), a Revista Brasileira do Ensino da Química (2012), e a Revista Virtual de Química (2012).

Muitos são os problemas que precisam ser discutidos e resolvidos com relação à química no ensino médio. Problemas que envolvem desde a seriação dos programas, permeando 
a relação dos conteúdos entre si e com o cotidiano dos alunos, até as estratégias de abordagem de conteúdos específicos, tais como: a apresentação do modelo quântico do átomo para alunos das séries iniciais, a concepção de estado de equilíbrio químico, a noção de ligação química pelo modelo da teoria do octeto de elétrons, ausência de aulas demonstrativas e experimentais e até mesmo de interdisciplinaridade, etc. Muitas vezes, dá-se ênfase à simplificação de conceitos, sugerindo-se que os alunos não tem condições de compreendê-los. Entretanto, a simplificação demais conduz a conceitos falsos, o que compromete a construção de modelos mentais das leis da natureza pelos alunos. Em outros casos, o conhecimento é dogmatizado e os alunos são dispensados de pensar e apenas devem aceitar e memorizar os tópicos. O professor precisa buscar um meio termo, um compromisso entre a exatidão e a simplicidade dos fatos químicos.

Uma maneira bastante interessante de se transmitir essa disciplina, buscando sua melhor compreensão por parte do alunado consiste na apresentação de experimentos práticos sobre os diferentes assuntos pertinentes à disciplina. Essa velha fórmula (vincular a teoria à prática) sempre pautou a dinâmica na relação ensinar e aprender, especialmente para disciplinas essencialmente experimentais como é a química. O problema é que, em muitas escolas, falta estrutura suficiente tais como, laboratórios, equipamentos adequados, reagentes e soluções, que possibilite a articulação da teoria à prática.

Diante desse contexto, alguns autores em nosso estado, preocupados com essa realidade, já lançaram algumas obras (LIMA; MACIEL, 2011; MACIEL; LIMA, 2011) que possibilitam ao professor do ensino médio desenvolver a disciplina na sala de aula através de experimentos com materiais alternativos. Este trabalho também tem esse propósito, ou seja, dinamizar os conteúdos de química, contextualizando-os, demonstrando as reações químicas e mostrando os produtos que são consumidos no cotidiano. Parte-se de uma metodologia diferente, a qual deverá ser construída de acordo com a própria realidade do aluno, sendo os experimentos registrados por eles em câmaras digitais para postagem na internet ou para apresentações futuras.

\section{PARTE EXPERIMENTAL}

Uma câmara na mão e uma ideia na cabeça. Bastam esses motivos iniciais para o desenvolvimento deste trabalho, acrescidos de alguns materiais de laboratório ou materiais alternativos, além da disposição dos alunos bolsistas dos programas Programa Institucional de Bolsas de Iniciação Científica para o Ensino Médio (PIBIC-EM), do Colégio Universitário e Programa Institucional de Bolsa de Iniciação à Docência (PIBID), do Curso de Química Licenciatura, mostrados na figura 1. Para cada vídeo produzido foram diversos ensaios, erros, repetições, ajustes e a edição final do produto.

Figura 1 - Equipe de alunos dos programas PIBICEM e PIBID-Química.

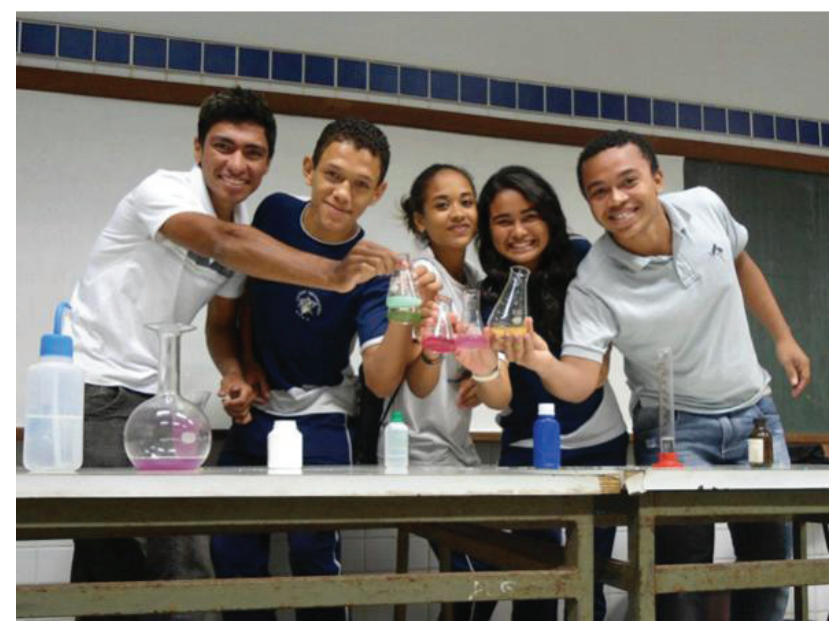

Fonte: Fotografia Elaborada pelos autores

\subsection{Construção do primeiro experimento}

Os materiais utilizados para desenvolvimento do primeiro experimento foram os seguintes: câmara digital com função de gravação de vídeos, balão de fundo chato, chapa aquecedora, luvas de proteção, garrafa PET com tampa.

Esse experimento foi construído seguindo as etapas relacionadas a seguir: uma quantidade de água foi aquecida em balão de fundo chato com auxílio de uma manta aquecedora. Após fervura da água, parte da água quente foi transferida para dentro da garrafa PET, na qual permaneceu por aproximadamente 30 segundos. Depois desse período, a garrafa PET foi esvaziada, tampada e levada imediatamente para debaixo da torneira com água corrente natural. Todas essas etapas foram registradas, comentadas e minuciosamente discutidas pelos alunos quanto aos resultados obtidos. Posteriormente elas foram repassadas para um computador com um programa específico para montagem da edição final.

\subsection{Construção do segundo experimento}

Os materiais utilizados para desenvolvimento do segundo experimento foram os seguintes: uma câmara digital com função de gravação de vídeos, liquidificador, 7 erlenmeyers de $125 \mathrm{~mL}$, 1 conta gotas, coador, repolho roxo, álcool etílico, soluções de ácido muriático, vinagre, leite de magnésia, amoníaco e soda cáustica.

A construção do experimento se deu da seguinte forma: primeiro os alunos obtiveram o extrato do repolho roxo, passando o mesmo em liquidificador com álcool etílico e filtrado com auxílio de um coador. Após esse procedimento, foram adicionadas 20 gotas do extrato do repolho roxo em cada uma das seguin- 
tes soluções: ácido muriático, vinagre, leite de magnésia, amoníaco e soda cáustica. Em cada adição do extrato à solução, os alunos comentavam em qual solução se adicionava o extrato e o porquê dos resultados obtidos após a mistura. Como no primeiro vídeo, a versão final foi montada em um computador através de um programa específico de edição.

\section{RESULTADOS E DISCUSSÃO}

O primeiro experimento apresentou, de uma forma simples e rápida, como se dá relação existente entre duas propriedades gasosas: temperatura e volume. A garrafa PET foi utilizada nessa demonstração por se tratar de um recipiente cujas paredes são maleáveis e não rígidas, para termos a noção da variação de volume do gás. Ao se adicionar a água quente no interior da garrafa, desejava-se que o ambiente interno da mesma estivesse a uma temperatura acima da temperatura ambiente, mesmo após a retirada da água, pois o ar que permanecia dentro do recipiente devidamente tampado era um ar quente. Nesse momento obteve-se o estado inicial do gás com um volume V1 e uma temperatura T1. Ao se colocar a garrafa PET sob a torneira com água corrente, as paredes da mesma se contraíram rapidamente devido à mudança brusca de temperatura ocorrida, enfatizando a relação diretamente proporcional entre a temperatura e o volume do gás, ou seja, diminuiu a temperatura gasosa logo o seu volume também diminui $\left(T_{2}\right.$ e $\left.V_{2}\right)$, justificando o emprego da equação geral dos gases (Equação 1):

$$
\frac{P_{1} \cdot V_{1}}{T_{1}}=\frac{P_{2} \cdot V_{2}}{T_{2}}
$$

A terceira propriedade gasosa que aparece na Equação 1 , nesse caso a pressão, se manteve constante durante toda a transformação gasosa.

Na gravação desse vídeo, os alunos, além de demonstrarem o experimento, explicam cada passo do mesmo e discutem os resultados obtidos, a relação entre as propriedades investigadas e as implicações que decorrem dessas transformações.

Com relação ao desenvolvimento do segundo experimento, os alunos perceberam as propriedades indicativas do extrato do repolho roxo em cada um dos frascos que continham as soluções de substâncias ácidas ou básicas. O repolho roxo, nesse caso, funciona como um indicador natural de ácido e base. Para cada meio aquoso utilizado, este adquiria uma cor diferente, dependendo da concentração de $\mathrm{H}^{+}$presente na solução, indicando a acidez ou alcalinidade (fraca ou forte) dos meios envolvidos. O experimento simples demonstrou um pequena noção de acidez e alcalinidade, bem como as formas alternativas de verificar o pH do meio utilizando tão somente um indicador natural ácido/base. Todas as etapas do experimento, desde a obtenção do extrato do repolho, passado em liquidificador juntamente com o álcool, até a adição de pequenas alíquotas em cada solução empregada, foram devidamente filmadas, refilmadas, editadas e postadas na internet, juntamente com o primeiro vídeo relatado anteriormente.

Além disso, o conhecimento do $\mathrm{pH}$ das soluções é de extrema importância, pois nos sistemas biológicos, corpos hídricos, solos e alimentos podemos determinar a concentração de íons $\mathrm{H}^{+}$(de acordo com a Equação 2 ) que poderão causar problemas ou não de acordo com os valores encontrados. Também nas atividades do homem, como indústria, estações de tratamento de água, agricultura e outras é sempre importante controlar rigorosamente os valores do $\mathrm{pH}$ por questões de saúde e econômicas.

$$
p H=-\log \left[H^{+}\right]
$$

\section{CONSIDERAÇÕES FINAIS}

Diante das propostas iniciais apresentadas pelo projeto de Iniciação Científica Júnior, é perfeitamente possível concluir que os resultados estão sendo altamente satisfatórios, haja vista que já houve um grande incentivo à vocação científica, à pesquisa bibliográfica e a procura aos sites de busca por parte dos alunos selecionados no projeto. Também foram proporcionados aos bolsistas a aprendizagem de técnicas e métodos científicos em laboratório, bem como estímulo ao desenvolvimento de sua criatividade. Como os trabalhos ainda estão sendo desenvolvidos, estamos planejando a criação de, pelo menos, mais dez vídeos com assuntos relacionados à química do $2^{\circ}$ e $3^{\circ}$ anos do ensino médio, articulando um processo entre a pesquisa e o processo da construção didática. Além disso, o estímulo aos estudantes do ensino médio e aos alunos da graduação, que também participam desse processo de investigação científica e da criação digital, estreitaram e otimizaram a capacidade e o enraizamento da pesquisa científica entre essas duas modalidades de ensino (médio e superior), desenvolvendo com isso um programa de educação científica e tecnológica nesta Instituição de Ensino, estimulando diretamente o aumento da produção científica no Colégio Universitário da UFMA. Outro fator importante é que as atividades de pesquisa desenvolvidas ao longo do ano de 2012 em nenhum momento entraram em conflito com as atividades discentes dos jovens pesquisadores.

\section{REFERÊNCIAS}

GRUPO ÁTOMO E ALÍNEA. Disponível em: <http://www.grupoatomoealinea.com.br/ rebeq/index.asp>. Acesso em: 24 set. 2012. 
LIMA, J. B.; MACIEL, A. P. Experimentos de química com materiais alternativos para a educação básica. São Luís: Edufma, 2011.

MACIEL, A. P.; LIMA, A. P. Alternativas para o ensino de química na educação básica. São Luís: Edufma, 2011.

QUÍMICA NOVA NA ESCOLA. 2012. Disponível em: <http://qnesc.sbq.org.br/online/ qnesc01/>. Acesso em: 23 set. 2012.

REVISTA BRASILEIRA DO ENSINO DA

QUÍMICA. 2012. Disponível em: < http:// rebeq. revistascientificas.com.br/sobre.asp>. Acesso em: 24 set. 2011.

REVISTA VIRTUAL DE QUÍMICA. 2012.

Disponível em: <http://www.uff.br/RVQ/ index.php/rvq>. Acesso em: 24 set. 2011.

SOCIEDADE BRASILEIRA DE QUÍMICA.

Disponível em: <http://www.sbq.org.br/

filiais/index.php>. Acesso em: 23 set. 2012. Disponível em: <http://www.sbq. org.br/reunioes.php>. Acesso em: 23 set. 2011. 